\title{
Article \\ TBO Degradation by Heterogeneous Fenton-like Reaction Using Fe Supported over Activated Carbon
}

\author{
Brahim Samir ${ }^{1, *} \mathbb{\infty}$, Soumia Bakhta ${ }^{2}$, Nabil Bouazizi ${ }^{1} \mathbb{1}$, Zahra Sadaoui $^{2}$, Ouiza Allalou ${ }^{2}$, Franck Le Derf ${ }^{1}$ \\ and Julien Vieillard ${ }^{1}$ (D) \\ 1 Laboratoire de Chimie Organique, Normandie University, UNIROUEN, INSA Rouen, CNRS, \\ COBRA (UMR 6014), 55 Rue Saint Germain, 27000 Évreux, France; nabil.bouazizi2@univ-rouen.fr (N.B.); \\ franck.lederf@univ-rouen.fr (F.L.D.); julien.vieillard@univ-rouen.fr (J.V.) \\ 2 Laboratory of Reaction Engineering, Faculty of Mechanical and Processes Engineering, University of Sciences \\ and Technology Houari-Boumediene, BP No. 32, El alia, Bab Ezzouar, Algiers 16111, Algeria; \\ soumia.bakhta64@gmail.com (S.B.); sadaouizahra@yahoo.fr (Z.S.); ouiza_75@yahoo.fr (O.A.) \\ * Correspondence: brahim.samir@univ-rouen.fr
}

Citation: Samir, B.; Bakhta, S.; Bouazizi, N.; Sadaoui, Z; Allalou, O.; Le Derf, F; Vieillard, J. TBO Degradation by Heterogeneous Fenton-like Reaction Using Fe Supported over Activated Carbon. Catalysts 2021, 11, 1456. https:// doi.org/10.3390/catal11121456

Academic Editor: Vincenzo Vaiano

Received: 27 October 2021

Accepted: 25 November 2021

Published: 29 November 2021

Publisher's Note: MDPI stays neutral with regard to jurisdictional claims in published maps and institutional affiliations.

Copyright: (c) 2021 by the authors. Licensee MDPI, Basel, Switzerland. This article is an open access article distributed under the terms and conditions of the Creative Commons Attribution (CC BY) license (https:// creativecommons.org/licenses/by/ $4.0 /)$.

\begin{abstract}
This study reports on the synthesis, immobilization, and stabilization of iron $(\mathrm{Fe})$ particles in activated carbon (AC) from date stem material for the heterogeneous Fenton-like removal of hazardous pollutants from water. AC-Fe was synthesized through a simple and sustainable chemical reaction using and resulting in an environmentally friendly material (AC-Fe). X-ray diffraction (XRD), scanning electron microscopy (SEM), Fourier transform infrared spectroscopy (FTIR), X-ray photoelectron spectroscopy (XPS) and energy-dispersive X-ray analyses (EDX) were used to characterize the synthesized samples. XRD, FTIR and XPS results showed the successful incorporation of iron particles onto AC. SEM images indicated smooth surfaces with clearly visible Fe particles. Compared to pure $\mathrm{AC}, \mathrm{AC}-\mathrm{Fe}$ showed higher degradation rates of toluidine blue $\mathrm{O}$ (TBO) dye. The effects of the initial $\mathrm{pH}$ and $\mathrm{TBO}$ and $\mathrm{H}_{2} \mathrm{O}_{2}$ concentrations on TBO degradation were investigated. The AC-Fe catalyst proved highly efficient in the Fenton-like degradation of TBO (50 ppm), with the removal of up to $99 \%$ in $3 \mathrm{~min}$. This catalyst was used efficiently for up to four repeated cycles. The improved catalytic activity of AC-Fe was related to Fe particles for the generation of HO•. These results prove that date stems-a waste product from agriculture-are a suitable precursor for preparing an appropriate $\mathrm{AC}$ and catalyst and for eliminating dyes from an aqueous solution by a heterogeneous Fenton-like reaction. The above results open an interesting avenue for the development of functional green catalysts based on AC-Fe for pollution removal.
\end{abstract}

Keywords: Fenton reaction; wastewater treatment; iron; activated carbon; catalysis; toluidine blue $\mathrm{O}$

\section{Introduction}

Due to the rapid growth of industrialization around the world, environmental issues such as water pollution are overwhelming problems that have attracted global attention. The pollution of water by dyes is a serious problem in developed countries. While the manufacturing industries keep on developing, many synthetic dyes are extensively applied in printing, paper making, and the pharmaceutical and food industries, and they are very toxic and resistant to natural biodegradation [1]. In many cases, dyes such as nitrophenol, methylene blue, azoic colors, or toluidine blue (TBO) are found in wastewaters and can be discharged into natural surroundings because no effective treatment method is available. Among these toxic dyes, TBO is a phenothiazine class of dye extensively used in different fields for various purposes such as medicine, the textile industry, or biotechnology (Scheme S1) [2]. It can be used as a mediator of various chemical or biochemical reactions, as a fabric-coloring agent, and as a labeling agent to identify organisms. The structure of TBO is given in Scheme S1. Dye removal from wastewater is always a true challenge because synthetic dyes are stable compounds that are difficult to destroy by commonly 
used treatments. Despite low concentrations (less than $1 \mathrm{mg} / \mathrm{L}$ ), organic dyes are highly visible, reflecting their structural complexity and nature. In outer environments, dyes are very stable. They can be preserved in water for a long time and are a threat to nature [3]. In contrast to these drawbacks, traditional techniques including coagulation/flocculation [4], biological treatment [5], and chemical oxidation [6] are very difficult to apply to remove dyes during wastewater treatment.

Among these processes, Fenton and Fenton-like oxidations are considered very green and promising methods and have retained the attention of many researchers for wastewater treatment. Fenton-like oxidations consist of the use of reagents such as $\mathrm{Fe}^{2+}$ or $\mathrm{Fe}^{3+}$ and $\mathrm{H}_{2} \mathrm{O}_{2}$, which require very little energy as compared to other technologies [7]. Several consecutive reactions are involved.

Fenton's reaction is an oxidative reaction where hydroxyl radicals are produced by the catalytic decomposition of hydrogen peroxide in the presence of ferrous iron (Equation (1)). The reaction is based on electron transfer from $\mathrm{H}_{2} \mathrm{O}_{2}$ to ferrous ions [8]. The regeneration of ferrous ions in the presence of $\mathrm{H}_{2} \mathrm{O}_{2}$ and hydroperoxyl radical ( $\mathrm{HO} \cdot$ ) can be considered an advantage for Fenton's reaction in terms of further degradation by ferrous ions. Unfortunately, Fenton's reaction requires an additional step, namely the separation and treatment of the iron sludge recovered at the end of the treatment process, which increases the overall operational cost. In order to overcome these drawbacks, an adequate solution consists of immobilizing the catalyst on inert support surfaces to avoid the catalyst-recovering step.

Many attempts have been made to immobilize nanoparticles on a porous solid to facilitate the access of $\mathrm{H}_{2} \mathrm{O}_{2}$ to the active center of the catalyst and improve its dispersion and separability.

Novel approaches have investigated iron-containing solids such as biochar [9], cellulose nanofibers [10], mesoporous silica matrix SBA [11], clays [12], zeolites [13], and montmorillonite [14] to prepare heterogeneous catalysts. Carbon-based catalysts-activated carbon [15], carbon nanotubes [16,17] and graphene [18] — have recently been considered as interesting catalyst supports for water treatment because of their high adsorption capability, good chemical stability, and excellent heat resistance $[19,20]$.

In this context, the aim of this work was the removal of toluidine blue (TBO) and the valorization of its residue using a green method (a Fenton-like reaction) with a sustainable catalyst immobilized on date-stem-derived AC and iron particles. Catalytic oxidation using a heterogeneous catalyst such as mesoporous AC was investigated. Techniques such as SEM, EDX, FTIR, and DRX were used to characterize the structural properties of the catalyst. To our knowledge, this is the first work in the literature that used iron immobilized on activated carbon in a heterogeneous Fenton's reaction for TBO degradation and date stems - a waste product from agriculture - to prepare AC. We also investigated the catalyst's stability to optimize the Fenton process by evaluating the effect of each operating parameter such as catalyst dosage, initial $\mathrm{pH}$, the hydrogen peroxide concentration, and the dye concentration. Additionally, the degree of mineralization of TBO was assessed by measuring the total organic carbon (TOC). Finally, to demonstrate the originality of the present work, our results were compared with other recently published works.

\section{Results and Discussion}

\subsection{Structural and Textural Properties}

The XRD diffractograms of the AC-Fe and AC materials are shown in Figure 1. The centralized extended signal at $25^{\circ}$ confirmed the presence of amorphous carbon. This peak was observed for $\mathrm{AC}$ and $\mathrm{AC}-\mathrm{Fe}$, suggesting no difference in the structures of AC and AC-Fe. This result can be explained by the low amount of Fe in AC, indicating that the AC structure was not altered by Fe incorporation. In addition, iron impregnated into AC was in the amorphous phase [21] (Figure 1). 


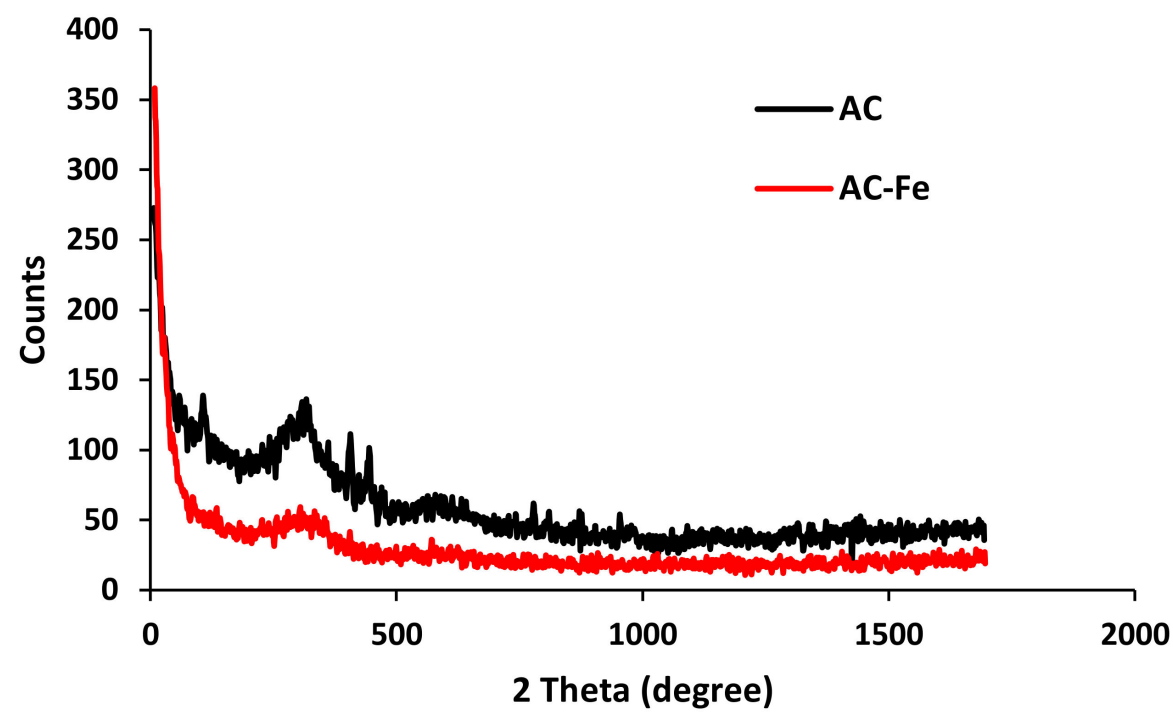

Figure 1. Comparative $\mathrm{X}$-ray diffractograms of $\mathrm{AC}$ and $\mathrm{AC}-\mathrm{Fe}$.

The surface morphologies of AC and AC-Fe were visualized by scanning electron microscopy (SEM); the images are shown in Figure 2. Well-developed pores with different open pore sizes were observed. It appeared that the outer surface of AC was full of cavities, probably due to the evaporation of $\mathrm{ZnCl}_{2}$ during the carbonization step [22]. Fe incorporation was confirmed by the presence of white clusters on the AC surface. The textural properties of the AC and its modified counterpart AC-Fe were determined; the results are summarized in Table 1, and adsorption isotherms are presented in Figure S2. The surface area and the pore volume of AC-Fe decreased after the incorporation of iron particles, indicating not only the successful immobilization of Fe but also satisfactory interactions of iron within the AC pores. The average pore size of AC-Fe was $3.3 \mathrm{~nm}$, in the range of mesoporous carbon (1 to $4 \mathrm{~nm}$ ) [23].
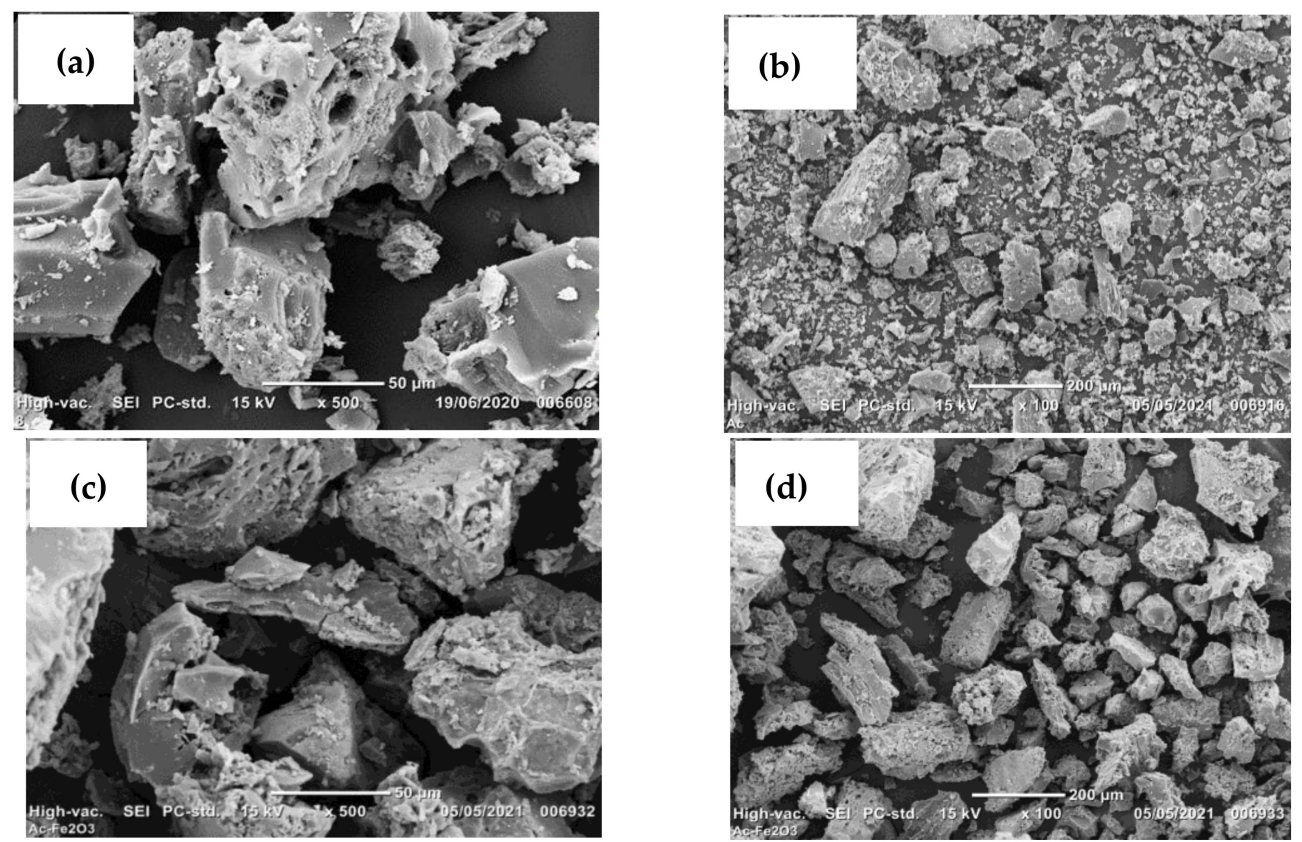

Figure 2. SEM images of different adsorbents based on activated carbon. $(\mathbf{a}, \mathbf{b}), \mathrm{AC} ;(\mathbf{c}, \mathbf{d}), \mathrm{AC}-\mathrm{Fe}$. 
Table 1. Surface area, pore volume, pore size, and pore distribution of $\mathrm{AC}$ and $\mathrm{AC}-\mathrm{Fe}$.

\begin{tabular}{cccc}
\hline \multicolumn{4}{c}{ BET } \\
\hline Sample & Surface Area $\left(\mathbf{m}^{2} / \mathbf{g}\right)$ & Pore Volume $\mathbf{( \mathbf { c m } ^ { 3 } / \mathbf { g } )}$ & Pore Size $(\mathbf{n m})$ \\
\hline AC & 1308.3 & 1.05 & 3.21 \\
\hline AC-Fe & 1069.3 & 0.89 & 3.33 \\
\hline
\end{tabular}

\subsection{Changes in Surface Chemistry Features}

The chemical composition of AC and the functionalized AC-Fe catalyst were observed by EDS (Figure 3 and Table 2). AC included high quantities of $\mathrm{C}$ and $\mathrm{O}$, and relatively median levels of inorganic elements such as $\mathrm{Na}, \mathrm{Si}, \mathrm{P}, \mathrm{S}, \mathrm{Cl}$, and $\mathrm{Zn}$. Importantly, EDS analysis of AC-Fe confirmed the successful immobilization of Fe particles, which was proved by the addition of Fe on the AC surface.
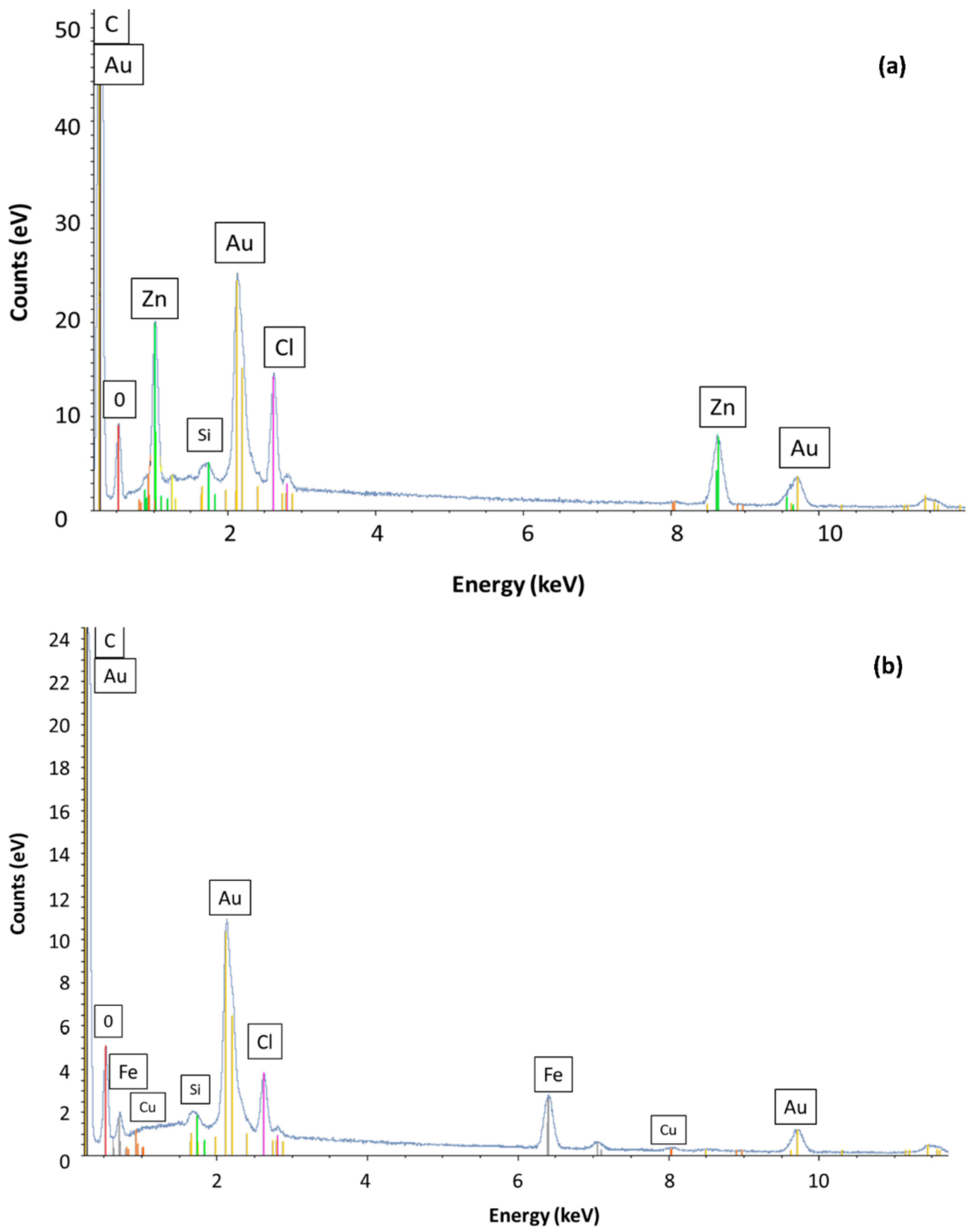

Figure 3. EDS spectra of (a), AC; (b), AC-Fe. A focus on the measured EDS area is presented in Figure S1. 
Table 2. EDS analysis of AC and AC-Fe.

\begin{tabular}{|c|c|c|c|c|c|c|}
\hline Sample & C (wt\%) & $\mathrm{O}(w \mathrm{t} \%)$ & Si (wt $\%)$ & $\mathrm{Fe}(w \mathrm{t} \%)$ & $\mathrm{Cl}(w \mathrm{t} \%)$ & $\mathrm{Cu}(w \mathrm{t} \%)$ \\
\hline $\mathrm{AC}$ & 74.89 & 5.31 & 0.44 & - & 2.77 & 0.20 \\
\hline $\mathrm{AC}-\mathrm{Fe}$ & 85.74 & 2.86 & 0.22 & 9.09 & 1.50 & 0.59 \\
\hline
\end{tabular}

FTIR spectra can provide valuable information about the functional groups of the materials. The FTIR spectra of AC and AC-Fe are represented in Figure 4. Overall, the FTIR spectra showed similar peaks, indicating that the structure was conserved before and after surface modification. The band observed at $600 \mathrm{~cm}^{-1}$ was attributed to the $\mathrm{Fe}-\mathrm{O}$ stretching vibration, which confirmed the incorporation of iron and/or iron oxides onto AC [24-26]. The bands at $1633 \mathrm{~cm}^{-1}$ were associated with the $\mathrm{C}=\mathrm{O}$ functional group. Moreover, a peak at $1384 \mathrm{~cm}^{-1}$ was recorded after iron incorporation due to the presence of the $\mathrm{NO}_{3}{ }^{-}$ stretching vibration. This last result can be explained by the unremoved $\mathrm{NO}_{3}{ }^{-}$retained in the AC during the impregnation step. To confirm these results, XPS analyses were employed to evaluate the surface chemistry of the samples. The broad peaks observed at $531.68,284.66,198.89$, and $711.54 \mathrm{eV}$ were associated with the O 1s, C 1s, C 2p, and Fe 2p layers, respectively. Regarding the XPS analysis of $\mathrm{AC}$, a $\mathrm{C} 1 \mathrm{~s}$ peak centered at around $284.66 \mathrm{eV}$ was attributed to the presence of $\mathrm{C}=\mathrm{C}$.

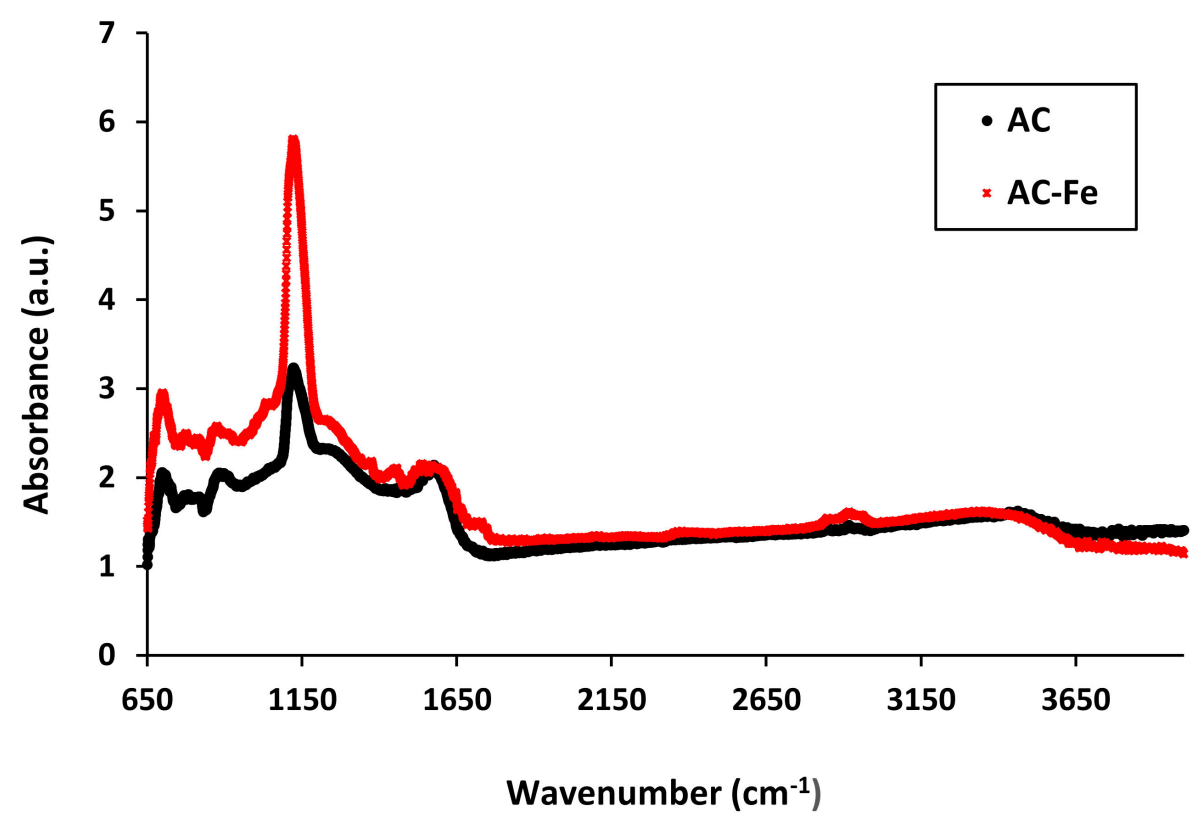

Figure 4. FTIR spectra of AC and AC-Fe.

A slight shift toward lower $\mathrm{eV}$ was recorded for the $\mathrm{O} 1 \mathrm{~s}$ peak, which appeared at $533.06 \mathrm{eV}$ and $532.03 \mathrm{eV}$ for AC and AC-Fe, respectively. This shift probably resulted from strong interactions between the $\mathrm{Fe}$ and $\mathrm{O}$ atoms. Another confirmation of $\mathrm{Fe}$ incorporation was obtained from the binding energies of Fe 2p 3/2, Fe 2p1/2 at 711.54, and $725 \mathrm{eV}$. The binding energy of Fe $2 \mathrm{p} 3 / 2$ at $711.54 \mathrm{eV}$ was related to $\mathrm{FeOOH}$ [27] (Figure 5). 

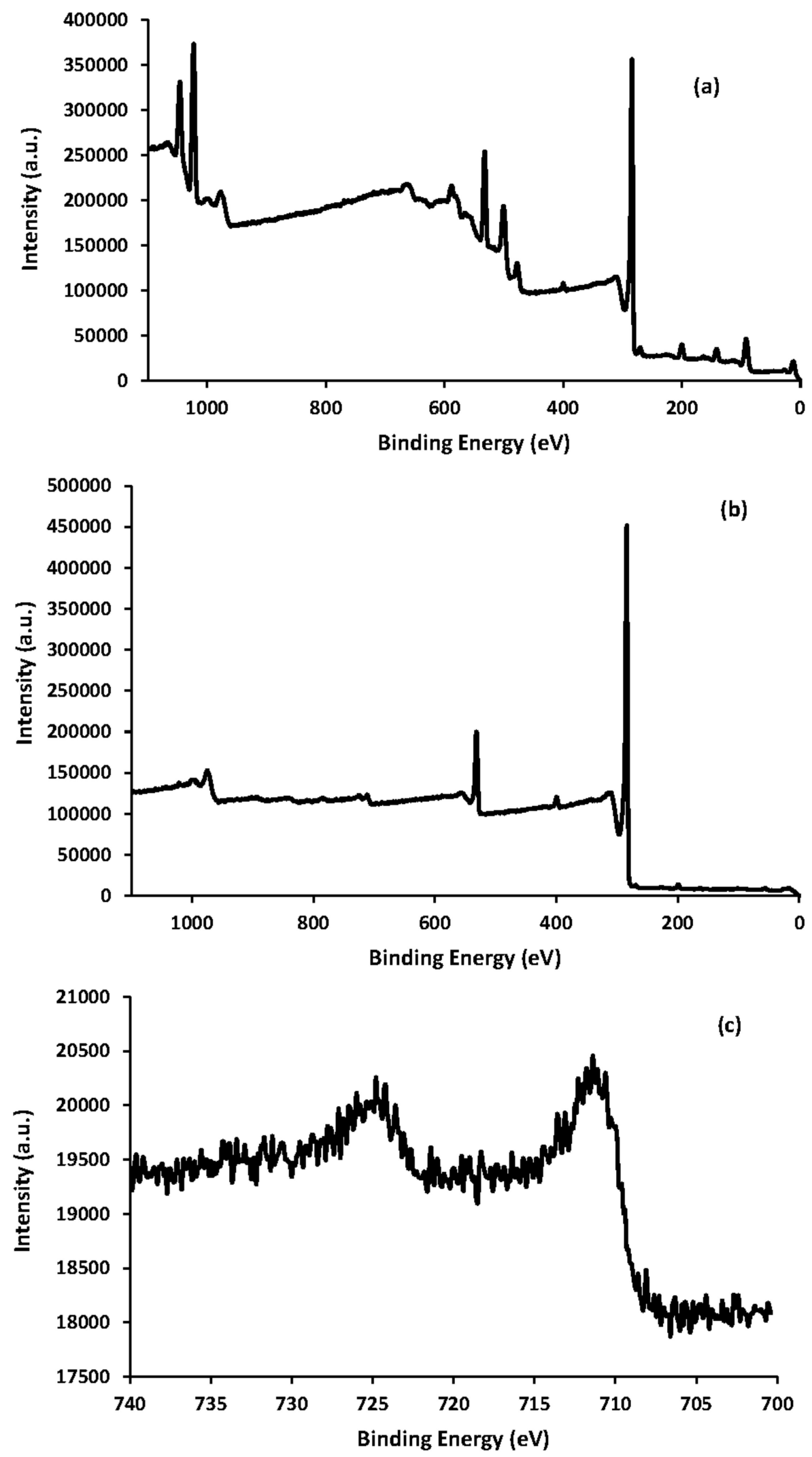

Figure 5. XPS spectra of (a), AC; (b), AC-Fe. (c), focus on Fe 2p spectra for AC-Fe.

\subsection{TBO Adsorption and Fenton Oxidation}

In order to evaluate the adsorption and catalytic activity of the prepared sample on dye removal efficiency, a series of experiments were performed by changing the initial 
AC-Fe concentration from 0.2 to $1.8 \mathrm{~g} / \mathrm{L}$ at a constant $\mathrm{H}_{2} \mathrm{O}_{2}$ concentration of $4 \mathrm{mmol} / \mathrm{L}$ at $20^{\circ} \mathrm{C}$ and pH 3.5. The results are summarized in Figures 6 and 7. The oxidation of TBO by $\mathrm{H}_{2} \mathrm{O}_{2}$ was very low (1\%). This can be explained by the negligible oxidation of $\mathrm{H}_{2} \mathrm{O}_{2}$ compared to $\mathrm{HO}$ [28]. In addition, the efficiency of the TBO removal by AC-Fe was $15 \%$ in the absence of $\mathrm{H}_{2} \mathrm{O}_{2}$ after 3 min of reaction. However, the presence of the AC-Fe catalyst + $\mathrm{H}_{2} \mathrm{O}_{2}$ showed a very high efficiency of TBO removal (99\%) in less than $3 \mathrm{~min}$, due to the generation of $\mathrm{HO}$ radicals resulting from the interaction of $\mathrm{H}_{2} \mathrm{O}_{2}$ and $\mathrm{AC}-\mathrm{Fe}$. This trend was confirmed when the AC-Fe concentration was $1.2 \mathrm{~g} / \mathrm{L}$ (Figure 7), suggesting increased numbers of $\mathrm{HO}$ radicals due to a higher decomposition rate of hydrogen peroxide [29]. When the catalyst concentration was increased up to $1.8 \mathrm{~g} / \mathrm{L}$, the efficiency of TBO removal slightly decreased to $98 \%$. This decreased efficiency can be explained by the coagulation of catalysts and the scavenging effect on $\mathrm{HO}$ due to the excessive iron species present in the solution, as supported by the reaction in Equation (1) [30,31]:

$$
\mathrm{Fe}^{2+}+\mathrm{HO} \rightarrow \mathrm{Fe}^{3+}+\mathrm{OH}^{-}
$$

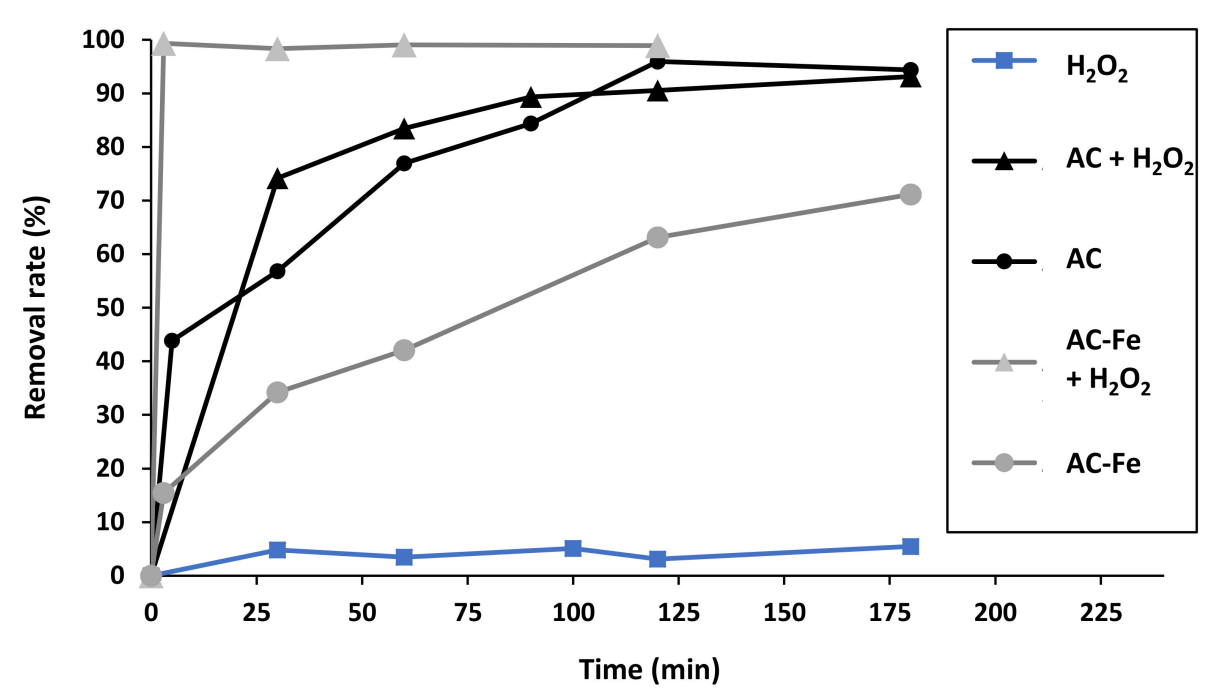

Figure 6. TBO removal upon treatment with $\mathrm{AC}$ and AC-Fe in the presence and absence of $\mathrm{H}_{2} \mathrm{O}_{2}$. Experimental conditions: $\mathrm{pH}=3.5,[\mathrm{TBO}]_{0}=50 \mathrm{mg} / \mathrm{L},\left[\mathrm{H}_{2} \mathrm{O}_{2}\right]=4 \mathrm{mmol} / \mathrm{L},[\mathrm{AC}-\mathrm{Fe}]=1.2 \mathrm{~g} / \mathrm{L}$, reaction temperature $=20^{\circ} \mathrm{C}$.

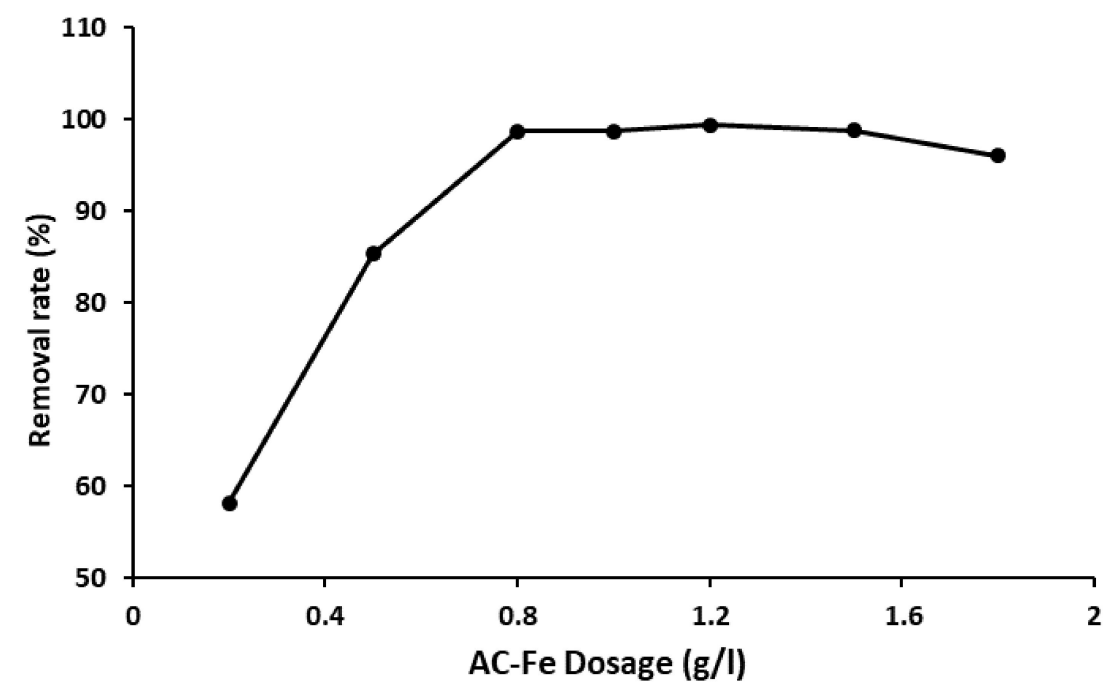

Figure 7. Effect of AC-Fe concentrations on $\mathrm{TBO}$ degradation. $\left(\mathrm{pH}=3.5,[\mathrm{TBO}]_{0}=50 \mathrm{mg} / \mathrm{L}\right.$, $\left[\mathrm{H}_{2} \mathrm{O}_{2}\right]=4 \mathrm{mmol} / \mathrm{L}$, reaction temperature $=20^{\circ} \mathrm{C}$ ). 


\subsubsection{Effect of $\mathrm{H}_{2} \mathrm{O}_{2}$}

The effect of different $\mathrm{H}_{2} \mathrm{O}_{2}$ doses on TBO removal was investigated by varying the initial $\mathrm{H}_{2} \mathrm{O}_{2}$ concentration from $2 \mathrm{mmol} / \mathrm{L}$ to $8 \mathrm{mmol} / \mathrm{L}$. As showed in Figure 8, TBO elimination efficiency increased from $96 \%$ to $99 \%$ in 3 min when the $\mathrm{H}_{2} \mathrm{O}_{2}$ dosage was increased from 1 to $2 \mathrm{mmol} / \mathrm{L}$. These results are attributable to the increases in $\mathrm{HO}$ radicals generated by the increased $\mathrm{H}_{2} \mathrm{O}_{2}$ concentration. However, the TBO removal decreased when the $\mathrm{H}_{2} \mathrm{O}_{2}$ concentration was increased from 2 to $6 \mathrm{mmol} / \mathrm{L}$, from $99.33 \%$ for $2 \mathrm{mmol} / \mathrm{L}$ to $90.30 \%$ for $6 \mathrm{mmol} / \mathrm{L}$. This can be explained by the production of less reactive species such as $\mathrm{HO}_{2}$. due to the scavenging effect and the auto-decomposition of $\mathrm{H}_{2} \mathrm{O}_{2}$ into $\mathrm{O}_{2}$ and $\mathrm{H}_{2} \mathrm{O}$ (Equations (2) and (3)) $[28,32]$. Thus, the optimal $\mathrm{H}_{2} \mathrm{O}_{2}$ concentration depends on the type and degree of the concentration of contaminants and ferrous ions [33].

$$
\begin{gathered}
\mathrm{H}_{2} \mathrm{O}_{2}+\mathrm{HO} \rightarrow \mathrm{H}_{2} \mathrm{O}^{\cdot}+\mathrm{H}_{2} \mathrm{O} \\
\mathrm{HO}_{2}+\mathrm{HO}^{\cdot} \rightarrow \mathrm{H}_{2} \mathrm{O}+\mathrm{O}_{2}
\end{gathered}
$$

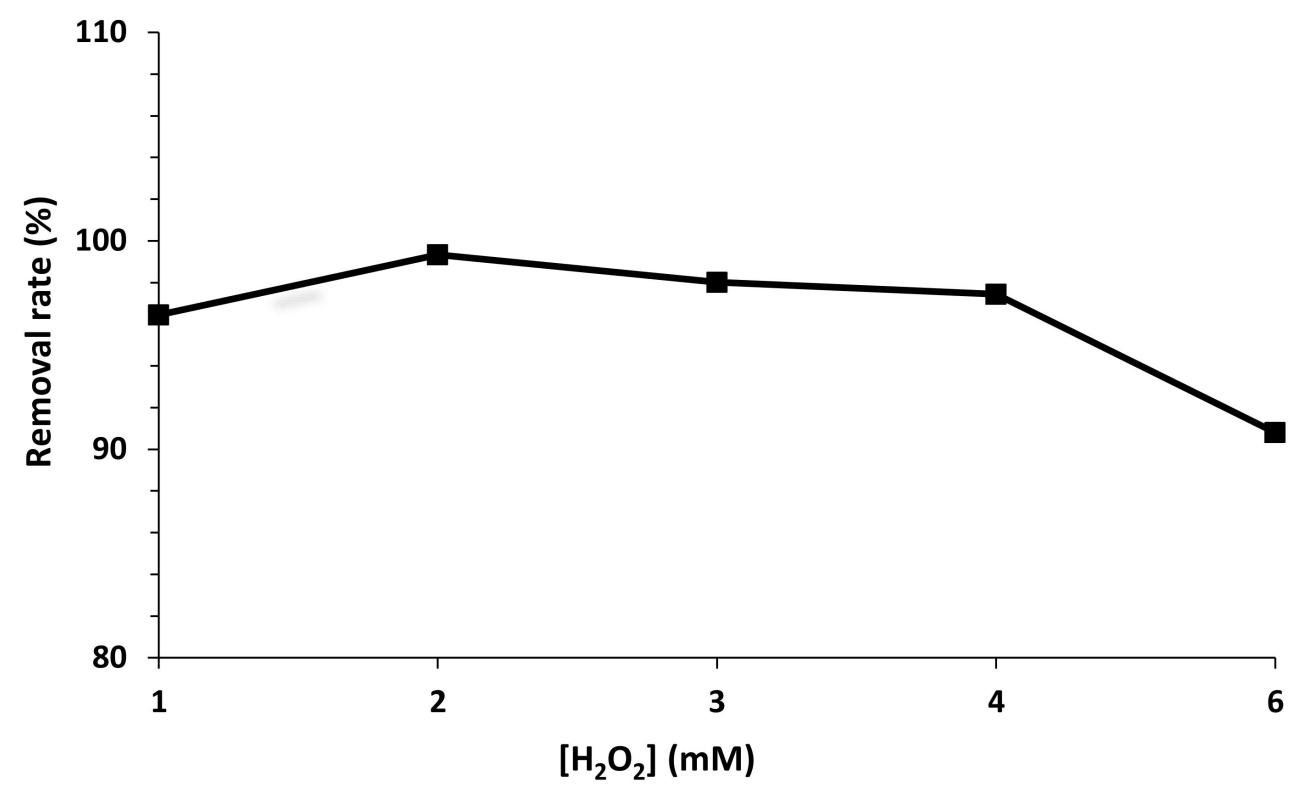

Figure 8. Effect of the $\mathrm{H}_{2} \mathrm{O}_{2}$ concentration on Fenton's reaction with AC-Fe. $\left(\mathrm{pH}=3.5\right.$, $[\mathrm{TBO}]_{0}=50 \mathrm{mg} / \mathrm{L}$, $[\mathrm{AC}-\mathrm{Fe}]=1.2 \mathrm{~g} / \mathrm{L}$, reaction temperature $=20^{\circ} \mathrm{C}$ ).

\subsubsection{Effect of the Initial TBO Concentration}

The study of the effect of the initial TBO concentration on the efficiency of heterogeneous Fenton-like oxidation is of great interest for eliminating dyes present at different concentrations in industrial waste. To study this effect, the initial TBO concentration was made to vary from 50 to $400 \mathrm{mg} / \mathrm{L}$, while keeping the previously optimized parameters constant $\left(\left[\mathrm{H}_{2} \mathrm{O}_{2}\right]=2 \mathrm{mmol} / \mathrm{L}\right)$ and $([\mathrm{AC}-\mathrm{Fe}]=1.2 \mathrm{~g} / \mathrm{L})$. The results are presented in Figure 9 . As the initial TBO concentration increased from 50 to $400 \mathrm{mg} / \mathrm{L}$, the efficiency of the TBO degradation decreased from $99.3 \%$ to $46.3 \%$ within the same time span of $3 \mathrm{~min}$. More particularly, the efficiency of the TBO removal was stable up to the initial concentration of $150 \mathrm{mg} / \mathrm{L}$, but decreased when the concentration ranged between 200 and $400 \mathrm{mg} / \mathrm{L}$. This can be explained by a lower number of $\mathrm{HO}$ radicals generated in the solution due to the competition between the large number of TBO molecules and $\mathrm{H}_{2} \mathrm{O}_{2}$ molecules in the solution for adsorption on the catalyst surface $[34,35]$ which led to a decreased efficiency in TBO removal. 


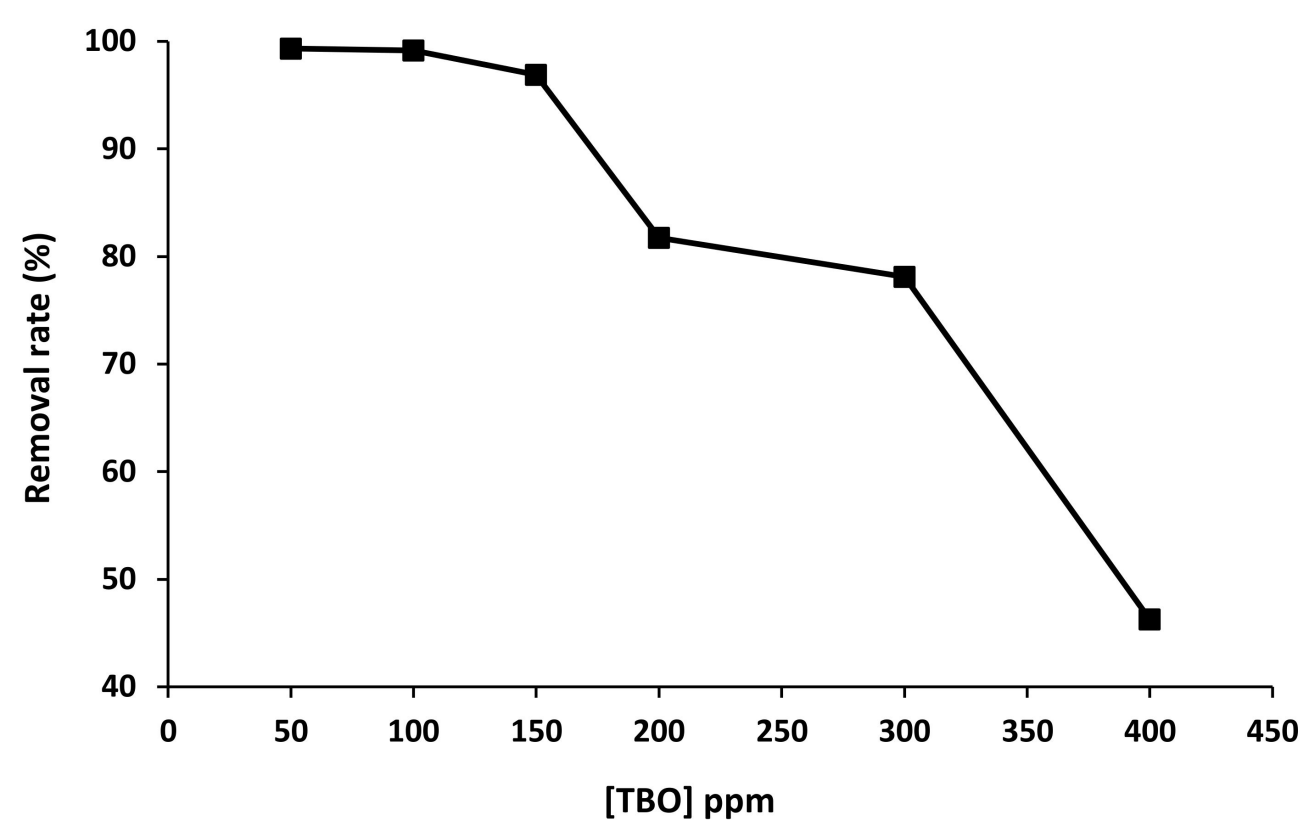

Figure 9. Effect of the initial TBO concentration on a Fenton-like reaction using AC-Fe. $(\mathrm{pH}=3.5$, $\left[\mathrm{H}_{2} \mathrm{O}_{2}\right]=4 \mathrm{mmol} / \mathrm{L},[\mathrm{AC}-\mathrm{Fe}]=1.2 \mathrm{~g} / \mathrm{L}$, reaction temperature $\left.=20^{\circ} \mathrm{C}\right)$.

\subsubsection{Effect of Initial $\mathrm{pH}$}

$\mathrm{pH}$ is one of the important operational parameters that significantly affects the removal of pollutants [36]. We expected the new heterogeneous Fenton catalysts to have an improved catalytic activity and a larger $\mathrm{pH}$ range compared to other catalysts. The $\mathrm{pH}$ of the solution regulates the rate of production of hydroxyl radicals and the amount of iron catalyst available at the solution/solid interface [37]. The effect of the initial $\mathrm{pH}$ on TBO degradation was investigated within a 2.0 to $9.7 \mathrm{pH}$ range (Figure 10). At $\mathrm{pH} 3.5$, maximum decolorization (99.3\%) was obtained for AC-Fe in 3 min, linked to the higher efficiency of used hydrogen peroxide, hence more $\mathrm{HO}$ radicals available to attack the dye molecules in the acidic solution. This optimal $\mathrm{pH}$ value was similar to that used for treating paranitrophenol with limonite [38] or when removing other pollutants by wet peroxidation using carbon [39] or iron-impregnated carbon [40] as catalysts. As expected, when the initial pH value increased from 3.5 to 9 , the efficiency of the TBO removal relatively decreased because hydrogen peroxide was less stable and broke down into molecular oxygen instead of being used to generate radicals [41]. In addition, ferrous ions can precipitate under alkaline conditions to form iron hydroxide $\left(\mathrm{Fe}(\mathrm{OH})_{3}\right)$ or hydrous ferric oxide $\left(\mathrm{Fe}_{2} \mathrm{O}_{3} \cdot \mathrm{nH}_{2} \mathrm{O}\right)$ [42]. These iron precipitates have a low efficiency in activating $\mathrm{H}_{2} \mathrm{O}_{2}$ to produce $\mathrm{HO}^{\bullet}$ radicals [43]. However, $\mathrm{pH}$ values below 2.0 were not suitable for TBO degradation in our AC- $\mathrm{Fe} / \mathrm{H}_{2} \mathrm{O}_{2}$ system. In fact, $\mathrm{H}^{+}$is easily captured by $\mathrm{H}_{2} \mathrm{O}_{2}$ to produce $\mathrm{H}_{3} \mathrm{O}_{2}{ }^{+}$at a lower $\mathrm{pH}$, so that the reaction between $\mathrm{H}_{2} \mathrm{O}_{2}$ and $\mathrm{Fe}$ (II) is limited. The final $\mathrm{pH}$ values in the solution after the Fenton-like reaction rapidly decreased from 2.0 (initial value) to 1.90 (final value) and from 9.7 (initial value) to 4.60 (final value). This was probably related to the influence of the acidic intermediates produced during the reaction. Similar results for the removal of methylene blue and orange II by Fenton's reaction have been reported [6] [44]. (Figure 10). Another possible cause of the $\mathrm{pH}$ change in the solution can be that $\mathrm{SO}_{4}{ }^{2-}, \mathrm{NO}^{3-}$ and $\mathrm{Cl}^{-}$ were formed during TBO mineralization and generated acidity [45]. The efficiency of TBO removal by AC-Fe was considered to be high even though the $\mathrm{pH}$ in the solution increased. Thus, the AC-Fe catalyst effectively removed dyes over a wide $\mathrm{pH}$ range, which would be a significant advantage in wastewater treatment. 


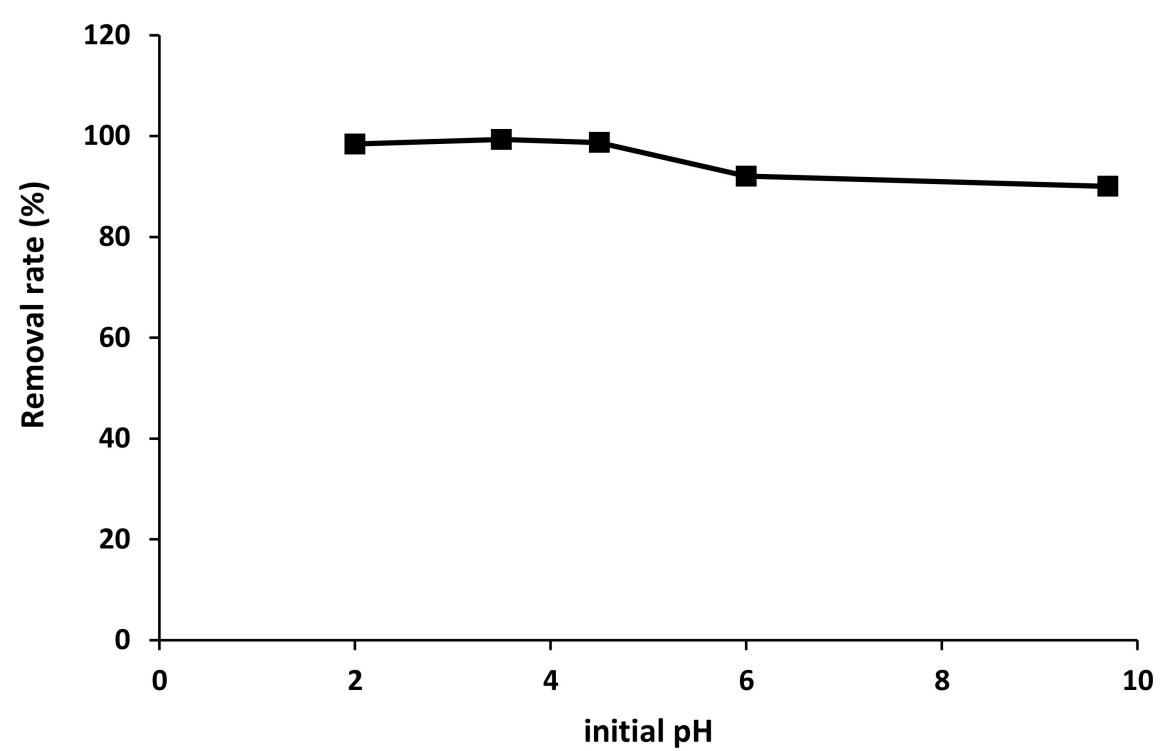

Figure 10. Effect of initial $\mathrm{pH}$ on the Fenton-like reaction with AC-Fe. Experimental conditions: $\left[\mathrm{H}_{2} \mathrm{O}_{2}\right]=4 \mathrm{mmol} / \mathrm{L},[\mathrm{TBO}]_{0}=50 \mathrm{mg} / \mathrm{L},[\mathrm{AC}-\mathrm{Fe}]=1.2 \mathrm{~g} / \mathrm{L}$, reaction temperature $=20^{\circ} \mathrm{C}$.

\subsection{Mineralization Study}

We evaluated the mineralization degree of TBO to determine if the generated intermediate compounds were degraded after the Fenton-like reaction. The total organic carbon (TOC) of the dye solution was measured after the optimized Fenton-like reaction. The following conditions were used to determine the mineralization degree: an initial dye concentration of $50 \mathrm{mg} / \mathrm{L}, \mathrm{pH} 3.5,4 \mathrm{mmol} / \mathrm{L}$ of $\mathrm{H}_{2} \mathrm{O}_{2}$, a temperature of $20^{\circ} \mathrm{C}$, and $1.2 \mathrm{~g} / \mathrm{L}$ of AC-Fe. The mineralization degree reached around $64 \%$ in $3 \mathrm{~min}$ for Fe-AC. This result is a potential signal indicating higher TBO mineralization. Consequently, the heterogeneous Fenton reaction reduced both the color and the organic matter in the solution.

\subsection{Stability and Reuse of the Catalyst}

Catalyst reuse is a crucial factor and an important point to be considered for the practical application of each catalyst material. The catalyst based on AC-Fe was evaluated on TBO degradation under normal conditions during the consecutive runs. As shown in Figure 11, the proposed catalyst retained $80 \%$ of the TBO degradation efficiency after four cycles. These results confirm the good stability and reutilization of the prepared AC-Fe catalysts. A slight decrease in catalyst efficiency was observed after the fourth cycle, attributable to the difficulty in completely removing the reaction residues and intermediates bound to the active site of the catalyst after the reaction. In addition, TOC measurements demonstrated a gradual decrease (from $64 \%$ to $52 \%$ TOC) when the number of cycles increased (Figure 11). Consequently, the AC-Fe catalyst can be considered as a recyclable and stable material for water treatment via the Fenton-like reaction.

The leaching of solid particles during wastewater treatment is dangerous for the environment because catalysts often release metallic ion particles [46]. For this reason, it was important to evaluate the iron leachability of the prepared AC-Fe catalyst. A leaching test showed that the concentration of iron ions present in the solution phase was less than $2 \mathrm{mg} / \mathrm{L}$.

Another confirmation was obtained by ICP measurements of iron leaching from the reused solution (Table S1). The iron lixiviation test showed a small quantity of Fe leaching that decreased after each reaction and was lower than the environmental standard (2 mg/L). 


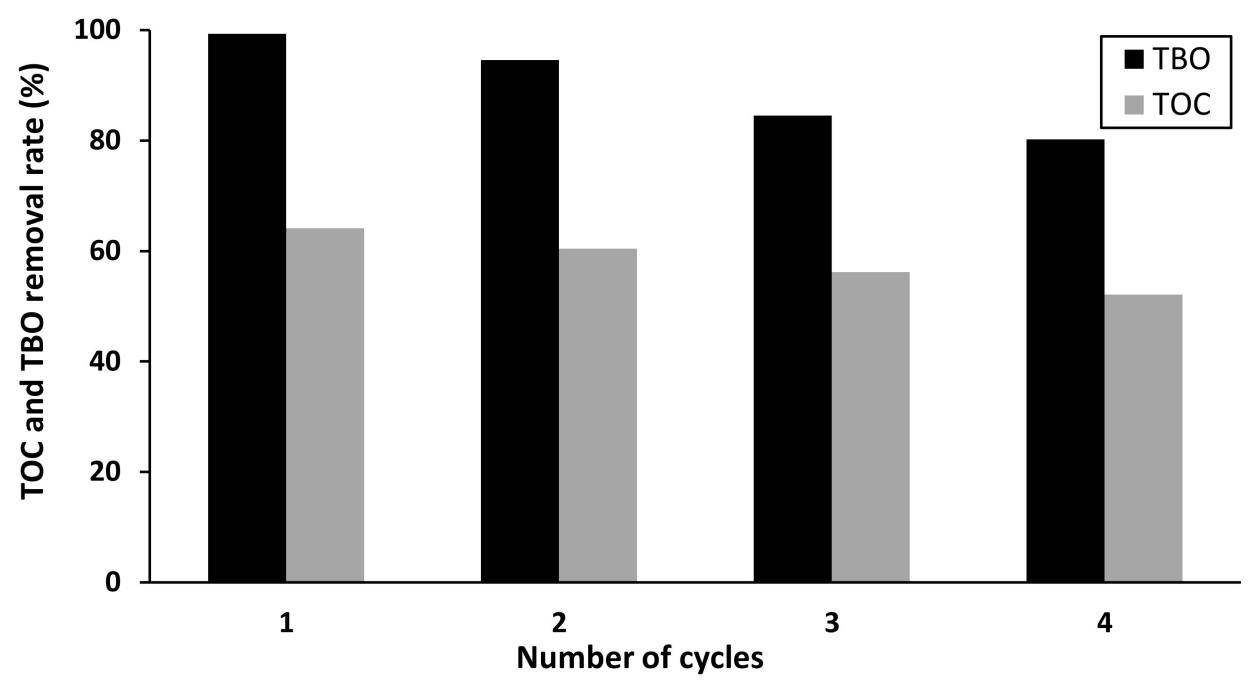

Figure 11. AC-Fe reusability for TBO removal from water. Experimental conditions: $\mathrm{pH}=3.5$, $\left[\mathrm{H}_{2} \mathrm{O}_{2}\right]=4 \mathrm{mmol} / \mathrm{L},[$ AC-Fe $]=1.2 \mathrm{~g} / \mathrm{L}$, reaction temperature $=20^{\circ} \mathrm{C}$.

This low amount of leached iron particles in the solution phase indicates that leaching was negligible and suggests a high stability of the AC-Fe catalyst, mainly due to the suitable surface modification employed during the iron incorporation process.

\section{Materials and Methods}

\subsection{Chemicals}

All chemicals, including toluidine blue (TBO), $\mathrm{ZnCl}_{2}$ and ferrous nitrate $\left(\mathrm{Fe}\left(\mathrm{NO}_{3}\right)_{3} \cdot 9 \mathrm{H}_{2} \mathrm{O}\right)$, were purchased from Sigma-Aldrich, Burlington, MA, USA. Hydrogen peroxide $\left(\mathrm{H}_{2} \mathrm{O}_{2}\right)$ was purchased from Fisher Chemicals, Illkirch-Graffenstaden, France. All chemicals were analytical reagents without any further purification, and the solutions were prepared using deionized water.

\subsection{Catalyst Preparation and Characterization}

Activated carbon was produced from date stems as waste biomass. It was prepared according to a previously reported method [47]. The sample was left in contact with the aqueous $\mathrm{ZnCl}_{2}$ solution (activating agent/raw material 2:1, w:w) at $70{ }^{\circ} \mathrm{C}$ for $4 \mathrm{~h}$ for chemical activation, under magnetic stirring, and then dried at $105^{\circ} \mathrm{C}$ for $24 \mathrm{~h}$. Then, the waste biomass was pyrolyzed at $600{ }^{\circ} \mathrm{C}$ in a muffle furnace for $1 \mathrm{~h}$. After cooling, the sample was washed many times with hydrochloric acid solution $(0.1 \mathrm{~mol} / \mathrm{L})$ and distilled water to eliminate activating agent residues and other inorganic species formed during the process. Finally, the resulting activated carbon, called AC, was dried at $105^{\circ} \mathrm{C}$ overnight and kept in a closed container [48].

For the functionalization step, AC powders were impregnated in metallic salt solution, following the incipient wetness impregnation method [49]. In more detail, $0.95 \mathrm{~g}$ of AC was mixed in a solution of $0.05 \mathrm{~mol} / \mathrm{L}$ of $\mathrm{Fe}\left(\mathrm{NO}_{3}\right)_{3} \cdot 9 \mathrm{H}_{2} \mathrm{O}$. Then, the mixture was magnetically stirred at room temperature for $24 \mathrm{~h}$. The modified AC was washed with deionized water several times to eliminate excess non-immobilized Fe. The resulting material-AC-Fe-was dried at $105^{\circ} \mathrm{C}$ overnight.

\subsection{Catalyst Characterization}

To specify the characteristics and properties of pure AC and its modified adsorbent counterpart, AC-Fe, several analyses were performed, such as Fourier Transform IR spectroscopy (FTIR), using a Tensor 27 (Bruker) spectrometer with a ZnSe ATR crystal in the 400 to $4000 \mathrm{~cm}^{-1}$ wavenumber range; X-ray diffraction (XRD) with a Bruker D8 X-ray diffractometer, using $\mathrm{CuK} \alpha$ radiation; and scanning electron microscopy (SEM), using a ZEISS EVO 15 scanning electron microscope. Atomic composition was assessed using 
an energy-dispersive $\mathrm{X}$-ray fluorescence device. The specific surface was estimated by nitrogen adsorption-desorption isotherms at $77 \mathrm{~K}$, using a Micromeritics tristar 3000 device. X-ray photoelectron spectroscopy (XPS), using ESCA-3400 Shimadzu, and the Al K alpha $\mathrm{X}$-ray source were employed for iron analysis on the surface of AC-Fe. Chemical elements were analyzed by inductively coupled plasma mass spectrometry (ICP-MS) in the Ciros CCD facility (Germany). The adsorbents were analyzed via $\mathrm{N}_{2}$ adsorption-desorption isotherms, which were used to determine the specific surface area and pore size distribution following the Brunauer-Emmett-Teller (BET) and Barret-Joyner-Halenda (BJH) methods, respectively, using a porosity analyzer from Micrometrics, model ASAP 2020 (USA) operating at $94.3 \mathrm{~K}$.

\subsection{Catalytic Experimental Procedure}

The degradation of TBO as a model pollutant was carried out using different concentrations of AC-Fe in the 0.1-1.8 g/L range, $\mathrm{H}_{2} \mathrm{O}_{2}$ concentrations in the $1-6 \mathrm{mmol} / \mathrm{L}$ range, TBO concentrations in the $50-400 \mathrm{mg} / \mathrm{L}$ range, and $\mathrm{pH}$ values in the $3-9$ range. Experimental batch runs were run in a $200 \mathrm{~mL}$ Pyrex glass beaker under magnetic stirring $(300 \mathrm{rpm})$ at room temperature. Samples were collected at regular time intervals and were centrifuged (4000 rpm, $10 \mathrm{~min}$ ). The concentration of residual TBO was determined using a UV-Vis spectrophotometer (Shimadzu, Columbia, MD, USA) at the characteristic TBO peak $(664 \mathrm{~nm})$. TOC analyses were performed, using a total organic carbon analyzer (Shimadzu, Total Organic Carbon Analyser-L). In addition, iron leaching analyses were performed by ICP-MS analysis, using an ICAP RQ instrument (Thermo Fisher Scientific, Waltham, MA, USA). All the above experiments were performed in 2 replicates.

\section{Conclusions}

This work focused on the transformation of date stem waste into a porous catalyst support via a simple and green method, to be used for water treatment using a heterogeneous Fenton-like reaction. SEM, XPS, FTIR, and EDX analyses revealed that Fe was successfully immobilized in AC. The prepared AC-Fe nanocomposite exhibited strong catalytic performances for TBO degradation by a Fenton-like reaction using AC-Fe combined with $\mathrm{H}_{2} \mathrm{O}_{2}$ and resulted in up to a $99 \%$ efficiency. The effects of various reaction parameters- $-\mathrm{H}_{2} \mathrm{O}_{2}$, $\mathrm{AC}-\mathrm{Fe}$, and $\mathrm{TBO}$ concentrations and initial $\mathrm{pH}-\mathrm{on}$ the $\mathrm{TBO}$ degradation were investigated. The optimal conditions were $4 \mathrm{mmol} / \mathrm{L}$ of $\mathrm{H}_{2} \mathrm{O}_{2}$ and $1.2 \mathrm{~g} / \mathrm{L}$ of AC-Fe for $50 \mathrm{mg} / \mathrm{L}$ of TBO at an initial $\mathrm{pH}$ of 3.5. Under these conditions, the efficiency of TBO removal and TOC conversion were $99 \%$ and $64 \%$, respectively, within 3 min of reaction time for the first run. The catalyst exhibited a good recycling capacity and has potential for application in TBO degradation. These interesting features of $\mathrm{AC}$-Fe open promising prospects for obtaining a wide variety of new, environmentally friendly catalysts for potential applications in wastewater treatment via Fenton-like reactions.

Supplementary Materials: The following are available online at https:/ /www.mdpi.com/article/ 10.3390/catal11121456/s1, Figure S1: focus on the area targeted for EDS analysis of Ac (a) and AC-Fe (b); Figure S2: BET nitrogen adsorption-desorption isotherms for AC and AC-Fe; Table S1: concentration of Fe released during consecutive cycle; Scheme S1: Chemical structure of TBO dye.

Author Contributions: Conceptualization, B.S. and N.B.; methodology, S.B.; software, J.V.; validation, B.S. and N.B.; resources, F.L.D.; writing—original draft preparation, B.S. and N.B.; writing—review and editing, B.S. and N.B. and J.V.; supervision, J.V.; project administration, J.V.; funding acquisition, Z.S., O.A., J.V. and F.L.D. All authors have read and agreed to the published version of the manuscript.

Funding: The authors acknowledge the Labex SYNORG (ANR-11-LABX-0029), the Région Normandie (CRUNCh and Sésa network) and ERDF (CosSésa) for support.

Data Availability Statement: The authors confirm that the data supporting the findings of this study are available within the article.

Conflicts of Interest: The authors declare no conflict of interest. 


\section{References}

1. Yao, T.; Qi, Y.; Mei, Y.; Yang, Y.; Aleisa, R.; Tong, X.; Wu, J. One-step preparation of reduced graphene oxide aerogel loaded with mesoporous copper ferrite nanocubes: A highly efficient catalyst in microwave-assisted Fenton reaction. J. Hazard. Mater. 2019, 378, 120712. [CrossRef]

2. Alpat, S.K.; Özbayrak, Ö.; Alpat, Ş.; Akçay, H. The adsorption kinetics and removal of cationic dye, Toluidine Blue O, from aqueous solution with Turkish zeolite. J. Hazard. Mater. 2008, 151, 213-220. [CrossRef]

3. Zheng, H.; Pan, Y.; Xiang, X. Oxidation of acidic dye Eosin Y by the solar photo-Fenton processes. J. Hazard. Mater. 2007, 141, 457-464. [CrossRef]

4. Guibal, E.; Roussy, J. Coagulation and flocculation of dye-containing solutions using a biopolymer (Chitosan). React. Funct. Polym. 2007, 67, 33-42. [CrossRef]

5. Kornaros, M.; Lyberatos, G. Biological treatment of wastewaters from a dye manufacturing company using a trickling filter. $J$. Hazard. Mater. 2006, 136, 95-102. [CrossRef] [PubMed]

6. Dutta, K.; Mukhopadhyay, S.; Bhattacharjee, S.; Chaudhuri, B. Chemical oxidation of methylene blue using a Fenton-like reaction. J. Hazard. Mater. 2001, 84, 57-71. [CrossRef]

7. Rodríguez, R.; Espada, J.J.; Pariente, M.I.; Melero, J.A.; Martínez, F.; Molina, R. Comparative life cycle assessment (LCA) study of heterogeneous and homogenous Fenton processes for the treatment of pharmaceutical wastewater. J. Clean. Prod. 2016, 124, 21-29. [CrossRef]

8. Barbusiński, K.; Majewski, J. Discoloration of azo dye Acid Red 18 by Fenton reagent in the presence of iron powder. Pol. J. Environ. Stud. 2003, 12, 151-155.

9. Huang, Q.; Song, S.; Chen, Z.; Hu, B.; Chen, J.; Wang, X. Biochar-based materials and their applications in removal of organic contaminants from wastewater: State-of-the-art review. Biochar 2019, 1, 45-73. [CrossRef]

10. Wang, G.; Xiang, J.; Lin, J.; Xiang, L.; Chen, S.; Yan, B.; Fan, H.; Zhang, S.; Shi, X. Sustainable Advanced Fenton-like Catalysts Based on Mussel-Inspired Magnetic Cellulose Nanocomposites to Effectively Remove Organic Dyes and Antibiotics. ACS Appl. Mater. Interfaces 2020, 12, 51952-51959. [CrossRef]

11. González-Rodríguez, J.; Gamallo, M.; Conde, J.J.; Vargas-Osorio, Z.; Vázquez-Vázquez, C.; Piñeiro, Y.; Rivas, J.; Feijoo, G.; Moreira, M.T. Exploiting the Potential of Supported Magnetic Nanomaterials as Fenton-like Catalysts for Environmental Applications. Nanomaterials 2021, 11, 2902. [CrossRef]

12. Hajjaji, W.; Pullar, R.C.; Labrincha, J.A.; Rocha, F. Aqueous Acid Orange 7 dye removal by clay and red mud mixes. Appl. Clay Sci. 2016, 126, 197-206. [CrossRef]

13. Ünnü, B.A.; Gündüz, G.; Dükkanc1, M. Heterogeneous Fenton-like oxidation of crystal violet using an iron loaded ZSM-5 zeolite. Desalin. Water Treat. 2016, 57, 11835-11849. [CrossRef]

14. Huang, Z.; Wu, P.; Gong, B.; Yang, S.; Li, H.; Zhu, Z.; Cui, L. Preservation of glutamic acid-iron chelate into montmorillonite to efficiently degrade Reactive Blue 19 in a Fenton system under sunlight irradiation at neutral pH. Appl. Surf. Sci. 2016, 370, 209-217. [CrossRef]

15. Bello, M.M.; Raman, A.A.A.; Asghar, A. Activated carbon as carrier in fluidized bed reactor for Fenton oxidation of recalcitrant dye: Oxidation-adsorption synergy and surface interaction. J. Water Process Eng. 2020, 33, 101001. [CrossRef]

16. Bounab, L.; Iglesias, O.; Pazos, M.; Sanromán, M.Á.; Gonzalez-Romero, E. Effective monitoring of the electro-Fenton degradation of phenolic derivatives by differential pulse voltammetry on multi-walled-carbon nanotubes modified screen-printed carbon electrodes. Appl. Catal. B Environ. 2016, 180, 544-550. [CrossRef]

17. Cleveland, V.; Bingham, J.P.; Kan, E. Heterogeneous Fenton degradation of bisphenol A by carbon nanotube-supported Fe $\mathrm{O}_{4}$. Sep. Purif. Technol. 2014, 133, 388-395. [CrossRef]

18. Yao, Y.; Cai, Y.; Lu, F.; Wei, F.; Wang, X.; Wang, S. Magnetic recoverable MnFe2O4 and MnFe2O4-graphene hybrid as heterogeneous catalysts of peroxymonosulfate activation for efficient degradation of aqueous organic pollutants. J. Hazard. Mater. 2014, 270, 61-70. [CrossRef]

19. Jain, A.K.; Gupta, V.K.; Bhatnagar, A.; Suhas, A. A comparative study of adsorbents prepared from industrial wastes for removal of dyes. Sep. Sci. Technol. 2003, 38, 463-481. [CrossRef]

20. Gupta, V.K.; Saleh, T.A. Sorption of pollutants by porous carbon, carbon nanotubes and fullerene-an overview. Environ. Sci. Pollut. Res. 2013, 20, 2828-2843. [CrossRef]

21. Gu, Z.; Fang, J.; Deng, B. Preparation and evaluation of GAC-based iron-containing adsorbents for arsenic removal. Environ. Sci. Technol. 2005, 39, 3833-3843. [CrossRef]

22. Deng, H.; Yang, L.; Tao, G.; Dai, J. Preparation and characterization of activated carbon from cotton stalk by microwave assisted chemical activation-Application in methylene blue adsorption from aqueous solution. J. Hazard. Mater. 2009, 166, $1514-1521$. [CrossRef]

23. Cheng, S.; Zhang, L.; Ma, A.; Xia, H.; Peng, J.; Li, C.; Shu, J. Comparison of activated carbon and iron/cerium modified activated carbon to remove methylene blue from wastewater. J. Environ. Sci. 2018, 65, 92-102. [CrossRef]

24. Tsoncheva, T.; Mileva, A.; Tsyntsarski, B.; Paneva, D.; Spassova, I.; Kovacheva, D.; Petrov, N. Activated carbon from Bulgarian peach stones as a support of catalysts for methanol decomposition. Biomass Bioenergy 2018, 109, 135-146. [CrossRef]

25. Wang, J.; Zhang, W.; Kang, X.; Zhang, C. Rapid and efficient recovery of silver with nanoscale zerovalent iron supported on high performance activated carbon derived from straw biomass. Environ. Pollut. 2019, 255, 113043. [CrossRef] [PubMed] 
26. Anjum, H.; Johari, K.; Gnanasundaram, N.; Appusamy, A.; Thanabalan, M. Impact of surface modification on adsorptive removal of BTX onto activated carbon. J. Mol. Liq. 2019, 280, 238-251. [CrossRef]

27. Grosvenor, A.P.; Kobe, B.A.; Biesinger, M.C.; McIntyre, N.S. Investigation of multiplet splitting of Fe $2 p$ XPS spectra and bonding in iron compounds. Surf. Interface Anal. Int. J. Devoted Dev. Appl. Tech. Anal. Surf. Interfaces Thin Film. 2004, 36, 1564-1574. [CrossRef]

28. Guimarães, J.R.; Maniero, M.G.; de Araújo, R.N. A comparative study on the degradation of RB-19 dye in an aqueous medium by advanced oxidation processes. J. Environ. Manag. 2012, 110, 33-39. [CrossRef]

29. Vickers, N.J. Animal communication: When I'm calling you, will you answer too? Curr. Biol. 2017, 27, R713-R715. [CrossRef] [PubMed]

30. Wu, H.; Dou, X.; Deng, D.; Guan, Y.; Zhang, L.; He, G. Decolourization of the azo dye Orange G in aqueous solution via a heterogeneous Fenton-like reaction catalysed by goethite. Environ. Technol. 2012, 33, 1545-1552. [CrossRef]

31. Carvalho, S.S.; Carvalho, N.M. Dye degradation by green heterogeneous Fenton catalysts prepared in presence of Camellia sinensis. J. Environ. Manag. 2017, 187, 82-88. [CrossRef] [PubMed]

32. Park, J.A.; Yang, B.; Park, C.; Choi, J.W.; van Genuchten, C.M.; Lee, S.H. Oxidation of microcystin-LR by the Fenton process: Kinetics, degradation intermediates, water quality and toxicity assessment. Chem. Eng. J. 2017, 309, 339-348. [CrossRef]

33. Navalon, S.; Alvaro, M.; Garcia, H. Heterogeneous Fenton catalysts based on clays, silicas and zeolites. Appl. Catal. B Environ. 2010, 99, 1-26. [CrossRef]

34. Azmi, N.H.M.; Ayodele, O.B.; Vadivelu, V.M.; Asif, M.; Hameed, B.H. Fe-modified local clay as effective and reusable heterogeneous photo-Fenton catalyst for the decolorization of Acid Green 25. J. Taiwan Inst. Chem. Eng. 2014, 45, 1459-1467. [CrossRef]

35. Jafari, A.J.; Kakavandi, B.; Jaafarzadeh, N.; Kalantary, R.R.; Ahmadi, M.; Babaei, A.A. Fenton-like catalytic oxidation of tetracycline by AC@ Fe3O4 as a heterogeneous persulfate activator: Adsorption and degradation studies. J. Ind. Eng. Chem. 2017, 45, 323-333. [CrossRef]

36. Fu, F.; Wang, Q.; Tang, B. Effective degradation of C.I. Acid Red 73 by advanced Fenton process. J. Hazard. Mater. 2010, 174, 17-22. [CrossRef]

37. Yao, Y.; Wang, L.; Sun, L.; Zhu, S.; Huang, Z.; Mao, Y.; Lu, W.; Chen, W. Efficient removal of dyes using heterogeneous Fenton catalysts based on activated carbon fibers with enhanced activity. Chem. Eng. Sci. 2013, 101, 424-431. [CrossRef]

38. Tao, H.C.; Wei, X.Y.; Zhang, L.J.; Lei, T.; Xu, N. Degradation of p-nitrophenol in a BES-Fenton system based on limonite. J. Hazard. Mater. 2013, 254, 236-241. [CrossRef]

39. Gomes, H.T.; Miranda, S.M.; Sampaio, M.J.; Figueiredo, J.L.; Silva, A.M.; Faria, J.L. The role of activated carbons functionalized with thiol and sulfonic acid groups in catalytic wet peroxide oxidation. Appl. Catal. B Environ. 2011, 106, 390-397. [CrossRef]

40. Zazo, J.A.; Casas, J.A.; Mohedano, A.F.; Rodríguez, J.J. Catalytic wet peroxide oxidation of phenol with a Fe/active carbon catalyst. Appl. Catal. B Environ. 2006, 65, 261-268. [CrossRef]

41. Du, W.; Xu, Y.; Wang, Y. Photoinduced degradation of orange II on different iron (hydr) oxides in aqueous suspension: Rate enhancement on addition of hydrogen peroxide, silver nitrate, and sodium fluoride. Langmuir 2008, 24, 175-181. [CrossRef]

42. Liang, C.; Liang, C.P.; Chen, C.C. $\mathrm{pH}$ dependence of persulfate activation by EDTA/Fe (III) for degradation of trichloroethylene. J. Contam. Hydrol. 2009, 106, 173-182. [CrossRef] [PubMed]

43. Kang, Y.W.; Hwang, K.Y. Effects of reaction conditions on the oxidation efficiency in the Fenton process. Water Res. 2000, 34, 2786-2790. [CrossRef]

44. Feng, J.; Hu, X.; Yue, P.L. Effect of initial solution $\mathrm{pH}$ on the degradation of Orange II using clay-based Fe nanocomposites as heterogeneous photo-fenton catalyst. Water Res. 2006, 40, 641-646. [CrossRef]

45. Huang, H.H.; Lu, M.C.; Chen, J.N. Catalytic decomposition of hydrogen peroxide and 2-chlorophenol with iron oxides. Water Res. 2001, 35, 2291-2299. [CrossRef]

46. Laiju, A.R.; Sivasankar, T.; Nidheesh, P.V. Iron-loaded mangosteen as a heterogeneous Fenton catalyst for the treatment of landfill leachate. Environ. Sci. Pollut. Res. 2014, 21, 10900-10907. [CrossRef]

47. Bakhta, S.; Sadaoui, Z.; Lassi, U.; Romar, H.; Kupila, R.; Vieillard, J. Performances of metals modified activated carbons for fluoride removal from aqueous solutions. Chem. Phys. Lett. 2020, 754, 137705. [CrossRef]

48. Allalou, O.; Miroud, D.; Belmedani, M.; Sadaoui, Z. Performance of surfactant-modified activated carbon prepared from dates wastes for nitrate removal from aqueous solutions. Environ. Prog. Sustain. Energy 2019, 38, S403-S411. [CrossRef]

49. Macías-Pérez, M.C.; Bueno-López, A.; Lillo-Rodenas, M.A.; de Lecea, C.S.M.; Linares-Solano, A. SO 2 retention on CaO/activated carbon sorbents. Part I: Importance of calcium loading and dispersion. Fuel 2007, 86, 677-683. [CrossRef] 